\title{
Parenteral nutrition providing a restricted amount of linoleic acid in severely burned patients: a randomised double-blind study of an olive oil-based lipid emulsion $v$. medium/long-chain triacylglycerols
}

\author{
A. García-de-Lorenzo ${ }^{1}$, R. Denia ${ }^{1}$, P. Atlan ${ }^{2}$, S. Martinez-Ratero ${ }^{1}$, A. Le Brun ${ }^{2}$, D. Evard ${ }^{2}$ and G. Bereziat ${ }^{3}$ \\ ${ }^{1}$ Hospital Universitario La Paz, Intensive Care Unit, Paseo de la Castellana, 261, 28046 Madrid, Spain \\ ${ }^{2}$ Baxter SAS, R\&D Nutrition, 6 avenue Louis-Pasteur, B.P. 56, 78311, Maurepas Cedex, France \\ ${ }^{3}$ Laboratory of Biochemistry, Saint-Antoine Hospital, 75012 Paris, France
}

(Received 24 September 2004 - Revised 3 February 2005 - Accepted 8 February 2005)

\begin{abstract}
It has been claimed that lipid emulsions with a restricted linoleic acid content can improve the safety of total parenteral nutrition (TPN). The tolerability of TPN and its effects on the metabolism of fatty acids were assessed in this prospective, double-blind, randomised study comparing an olive/soyabean oil long-chain triacylglycerol (LCT) with a medium-chain triacylglycerol (MCT)/LCT; 50:50 (w) based lipid emulsion in two groups (O and M, respectively; eleven per group) of severely burned patients. After resuscitation ( $48-72 \mathrm{~h}$ ), patients received TPN providing $147 \mathrm{~kJ} / \mathrm{kg}$ per d ( $35 \mathrm{kcal} / \mathrm{kg}$ per d) with fat $(1.3 \mathrm{~g} / \mathrm{kg}$ per $\mathrm{d})$ for $6 \mathrm{~d}$ Plasma fatty acids, laboratory parameters including liver function tests, and plasma cytokines were assessed before and after TPN. Adverse events encountered during TPN and the clinical outcomes of patients within the subsequent 6 months were recorded. With both lipid emulsions, the conversion of linoleic acid in its higher derivatives (di-homo- $\gamma$-linolenic acid) improved and essential fatty acid deficiency did not appear. Abnormalities of liver function tests occurred more frequently in the M (nine) than in the $\mathrm{O}$ (three) group ( $P=0 \cdot 04$, Suissa-Shuster test). Seven patients (four from group $\mathrm{O}$ and three from group $\mathrm{M}$ ) died as a consequence of severe sepsis 3-37d after completion of the $6 \mathrm{~d}$ TPN period. When compared with the surviving patients, those who died were older $(P=0.01)$ and hyperglycaemic at baseline $(P<0.001)$, and their plasma IL-6 levels continued to increase $(P<0 \cdot 04)$. Although fatty acid metabolism and TPN tolerability were similar with both lipid emulsions, the preservation of liver function noted with the use of the olive oil-based lipid emulsions deserves confirmation.
\end{abstract}

Burns: Parenteral nutrition: Lipid emulsion: Olive oil: Liver function tests

Burn trauma is one of the most severe physiological insults and thus consistently produces one of the most devastating responses to metabolic stress. Although a patient's early outcome is predominantly related to the extent of burn as well as age and comorbidities (Zawacki et al. 1979; Tobiasen et al. 1982), nutritional strategies may facilitate recovery with a possible reduction in death rate (Montegut \& Lowry, 1993; Pelaez et al. 1997). Although no clear specific nutritional recommendations have been decreed for burn patients (Deitch, 1995), the nature and quantity of nutritional intake are of critical choice in these patients, who are concomitantly hypermetabolic, inflamed and immunosuppressed, and are therefore highly sensitive to the risk of sepsis (Alexander, 1990; Barlow, 1994).

Several reports have demonstrated that an excessive lipid intake may adversely affect the immune system and clinical outcome in critically ill patients (Garcia-de-Lorenzo \& Culebras, 1992; Battistella et al. 1997; Weissman, 1999), including severely burned patients (Garrel et al. 1995). This relationship between high fat intake and impaired immune response has arisen from studies mainly implicating soyabean oil-based lipid emulsions because they are the most commonly used lipid source (Nordenstrom et al. 1979; Seidner et al. 1989; Freeman et al. 1990; Kinsella et al. 1990; Calder \& Newsholme, 1992; Sadeghi et al. 1999; Eritsland, 2000; Garnacho-Montero et al. 2002). Soyabean oil-based lipid emulsions are particularly rich in $n-6$ PUFA, namely linoleic acid (LA, 18:2n-6), and are consequently suspected of causing an imbalanced production of prostaglandins and other eicosanoids (Hageman et al. 1983; Spielmann et al. 1988; Kinsella et al. 1990), with the potential risk of worsening the pre-existing immunosuppressed and inflammatory state of critically ill patients (Sparkes, 1997; Schwacha \& Chaudry, 2002).

Alternatives to standard soyabean oil-based lipid emulsions are those with restricted LA content. A lipid emulsion that has recently become available is based on a mixture of olive oil and soyabean oil $(4: 1, \mathrm{~W}: \mathrm{G})$, and is characterised by its low content of LA (18\% of total fatty acids) and its high content of oleic acid, an $n-9$ MUFA (63\%). Clinical studies have already confirmed the nutritional and metabolic efficacy of this lipid emulsion, as well as its good global safety in different situations: from short-term total parenteral nutrition (TPN) in critically ill patients (Rossle et al. 1992; Reimer et al. 2001) and pre-term infants (Gobel et al. 2003) to longer periods of home parenteral 
nutrition in adults (De Francesco et al. 1999; Vahedi et al. 1999; Thomas-Gibson et al. 2004) and paediatric patients (Goulet et al. 1999).

To confirm the potential interest in this low LA-content lipid emulsion in critically ill patients, we performed a prospective double-blind trial in severely burned patients. To estimate the role of a restricted LA supply, a comparison was carried out with another lipid emulsion also characterised by its low LA content (26\% of total fatty acids; Lipofundina (B. Braun, Melsungen, Germany); 50:50 medium-chain triacylglycerol/long-chain triacylglycerol (MCT/LCT)). Use of this intravenous lipid emulsion is widely documented in many clinical circumstances, and it is routinely used in the intensive care unit (ICU).

\section{Methods}

The protocol was approved by the Committee on Human Rights in Research of the University Hospital 'La Paz' and was in accordance with regulations of European Good Clinical Practice.

\section{Patients and study design}

Adult patients with severe burns (Abbreviated Burn Severity Index $\geq 7$; Tobiasen et al. 1982) admitted to ICU were included, TPN usually being indicated for a duration of 5-7 d according to actual practice in the same centre (Herruzo-Cabrera et al. 1995). TPN was justified by the high energy requirements and a formal contraindication to enteral nutrition. Before receiving TPN, patients were resuscitated for a period of less than $3 \mathrm{~d}$ with Ringer's lactate or saline infusions associated with frozen plasma (Warden et al. 1973).

Patients were not included if they had pre-existing pathologies such as AIDS, chronic renal disease (creatininaemia $>2 \mathrm{mg} / \mathrm{dl}$ ), hepatic dysfunction (bilirubin above twice the upper limit of normal ( $>2$ ULN), alanine aminotransferase or aspartate aminotransferase $>4$ ULN, or prothrombin time $<50 \%$ ), lipid disorder (triacylglycerols $>250 \mathrm{mg} / \mathrm{dl}$ ) or any contraindication to the components of TPN. Patients who had been sedated with propofol were excluded because of its lipid emulsion excipient. All patients received similar wound-care treatment, including wound excision and skin-grafting of deep second- and third-degree wounds, mechanical ventilation, analgesia and antibiotic therapy.

Patients were enrolled into this prospective, controlled, doubleblind, randomised, monocentre study according to: (1) the centre's capacity for recruitment; (2) reference to previous clinical studies comparing the effect of olive-oil based and soyabean oil-based lipid emulsions on patients' plasma fatty acid profile as the primary criterion of efficacy.

\section{Parenteral nutrition}

Patients were randomly assigned into one of the two groups to receive exclusive parenteral nutrition (TPN) with either ClinOleic $20 \%$ (Baxter, Maurepas, France; group O) or Lipofundina MCT/ LCT $20 \%$ (B. Braun; group M) for $6 \mathrm{~d}$. The constituents of the two lipid emulsions are presented in Table 1.

The nutritive admixture was prepared daily in a designed formula by usual hospital practices, delivered in blind-labelled plastic bags and continuously infused for $24 \mathrm{~h}$ through a central catheter. To ensure that nutrition support was isoenergetic and iso-nitrogenous between groups, TPN (per $\mathrm{kg}$ usual body
Table 1. Composition of intravenous lipid emulsions

\begin{tabular}{lcc}
\hline & & \\
Per $100 \mathrm{ml}$ & ClinOleic $20 \%$ & MCT/LCT 20\% \\
\hline Soyabean oil LCT & $4 \mathrm{~g}$ & $10 \mathrm{~g}$ \\
Olive oil LCT & $16 \mathrm{~g}$ & - \\
MCT & Reimer et al. 2001; & $10 \mathrm{~g}$ \\
Egg phospholipids & $1 \cdot 2 \mathrm{~g}$ & $1 \cdot 2 \mathrm{~g}$ \\
Glycerol & $2 \cdot 25 \mathrm{~g}$ & $2.5 \mathrm{~g}$ \\
PUFA & $4 \mathrm{~g}$ & $6 \mathrm{~g}$ \\
MUFA & $13 \mathrm{~g}$ & $2 \mathrm{~g}$ \\
Saturated fatty acids & $3 \mathrm{~g}$ & $12 \mathrm{~g}$ \\
Linoleic acid/total fatty acids & $18 \%$ & $24 \%$ \\
\hline
\end{tabular}

MCT, medium-chain triacylglycerols; LCT, long-chain triacylglycerols.

weight per d) contained a total of $147 \mathrm{~kJ}$ with $0.25 \mathrm{~g} \mathrm{~N}$ delivered as Synthamin (Baxter). Lipids were administered at $1.3 \mathrm{~g} / \mathrm{kg}$ usual body weight per $\mathrm{d}$, and glucose at $4.3 \mathrm{~g} / \mathrm{kg}$ usual body weight per $\mathrm{d}$, providing $40 \%$ and $60 \%$ of patients' non-protein energy supply, respectively. Vitamins (Cernevit; Baxter, Maurepas, France), trace elements (Addamel; Fresenius Kabi, Bad Homburg, Germany) and electrolytes ( $\mathrm{Na}, \mathrm{K}$ ) were prescribed according to individual need.

\section{Plasma phospholipid fatty acid profiles}

Samples were taken before the first lipid infusion (D1) and 4-8h after the last one (D6). Samples were preserved at $-20^{\circ} \mathrm{C}$ in tubes containing $2 \mathrm{ml}$ plasma in $0.4 \mathrm{ml}$ solution containing butylated hydroxytoluene $(1 \mathrm{~g} / \mathrm{l}$ absolute ethanol) as an antioxidant. Plasma phospholipid fatty acids were measured as previously described by Driss et al. by using GLC on a Carlo Erba Chromatograph (Erba \& Sciences, Paris, France) equipped with a polar column (Omegawax Supelco Inc, Bellafonte, PA, USA) and a flame ionisation detector (Driss et al. 1988). The levels (\%) of each saturated fatty acid, MUFA and PUFA were determined. The arachidonic acid (AA):LA, sum of LA upper derivatives $\left(\sum n-6, \mathrm{C}>18+18: n-6\right)$ to LA, and $20: 3 n-6:$ AA ratios were calculated as reflecting the activities of $\delta 6$ - and $\delta 5$-desaturases. Triene/tetraene $(20: 3 n-9: 20: 4 n-6)$ and $n-3: n-6$ ratios were established as respective estimates of essential fatty acid deficiency (Holman, 1960) and cell membrane fluidity and immune function (Peck, 1994).

\section{Clinical and biological safety indices}

All patients were monitored for TPN intake, adverse events including septic events, and biochemical parameters including serum albumin, C-reactive protein, fibrinogen, glucose, urea, creatinine, $\mathrm{Na}, \mathrm{K}, \mathrm{Cl}^{-}$, haematology (haemoglobin, blood cell count, platelets) and lipids (total cholesterol, triacylglycerols) from the initial period to D6. Plasma concentrations of 'proinflammatory' (IL-6, TNF $\alpha$ ) and 'anti-inflammatory' (IL-1 receptor antagonist, IL-10) cytokines were quantitatively determined at D1 before the first lipid infusion and at D6, $4-8 \mathrm{~h}$ after the end of the last one, by ELISA (Quantikine; R\&D Systems Europe, Abingdon, Oxfordshire, UK).

Because liver function tests are considered to be critical safety parameters during the parenteral infusion of lipids (Cavicchi et al. 2000), we performed a detailed analysis of these parameters. Abnormalities were interpreted according to the following rule(s): 
1. Cholestasis: when a value above the ULN occurred during treatment and was observed for at least two parameters from conjugated bilirubin, alkaline phosphatases and $\gamma$-glutamyl transpeptidase.

2. Cytolysis: when a value $>2$ ULN of aspartate aminotransferase and/or alanine aminotransferase occurred during treatment.

\section{Adverse events and clinical outcome}

Septic events, multiple organ dysfunction score, duration of ventilation, morbidity, mortality and length of stay in ICU and in hospital were recorded during the double-blind period of treatment and by follow-up assessment after 6 months.

\section{Statistical analysis}

The results are expressed as means with their standard errors. SAS (SAS Institute Inc, Cary, NC, USA) for Windows was used for the analyses. A baseline (D1) comparison was made across treatments for clinical and laboratory characteristics of patients. For quantitative criteria, non-parametric methods were used. Comparisons between groups were assessed by the Wilcoxon rank sum test, the Wilcoxon signed rank test being used for intra-individual differences between D6 and baseline (D1).

For liver function test abnormalities, an exact unconditional test, the Suissa-Shuster's unconditional test, was applied (Suissa \& Shuster, 1985). This test was preferred to a $\chi^{2}$ test or a Fisher's exact test because the Fisher's exact test is known to be very conservative with small sample sizes, and the conditions for applying a $\chi^{2}$ test were not fulfilled (less than five for some cells/occurrences).

The analyses were conducted on the intention-to-treat group, and the level of significance was set at $P \leq 0 \cdot 05$.

\section{Results}

\section{Patient groups at baseline}

Having collecting their informed consent, twenty-two patients were included (eleven in each group). They had all been healthy before the burn injury. The two groups did not differ in age, BMI, gender ratio, total burned surface area or need for mechanical ventilation at baseline (Table 2). Some liver abnormalities were found in both patient groups (cholestasis: one case in group $\mathrm{O}$; cytolysis: two in group $\mathrm{O} v$. one in group $\mathrm{M}$ ). Baseline laboratory characteristics did not differ statistically between groups, except for a higher mean leucocyte count in group $\mathrm{M}$.

\section{Parenteral intake}

During the double-blind period, the average daily amount (per kg per d) of administered parenteral lipids as well as intakes of $\mathrm{N}$ and glucose were similar in the two groups (Table 3). The use of concomitant medications, including vitamins, trace elements, plasma substitutes, plasma protein fractions and blood and related products was not significantly different between the groups (data not shown).
Table 2. Patient characteristics at baseline for groups of patients randomised to receive olive-oil $(\mathrm{O})$ or medium-chain/long-chain triacylglycerol (M) based lipid emulsions

(Mean \pm SEM or $n$ )

\begin{tabular}{|c|c|c|c|c|c|}
\hline & \multicolumn{2}{|c|}{$\begin{array}{l}\text { Group O } \\
(n 11)\end{array}$} & \multicolumn{2}{|c|}{$\begin{array}{l}\text { Group M } \\
(n 11)\end{array}$} & \multirow[b]{2}{*}{$P$} \\
\hline & Mean & SEM & Mean & SEM & \\
\hline Age (years) & $49 \cdot 1$ & 4.6 & 39.9 & $5 \cdot 1$ & NS \\
\hline BMI $\left(\mathrm{kg} / \mathrm{m}^{2}\right)$ & $24 \cdot 4$ & 0.8 & $24 \cdot 7$ & $1 \cdot 1$ & NS \\
\hline Gender (male/female) ( $n$ ) & \multicolumn{2}{|c|}{$8 / 3$} & \multicolumn{2}{|c|}{$6 / 5$} & NS \\
\hline Inhalation trauma $(n)$ & \multicolumn{2}{|c|}{7} & \multicolumn{2}{|c|}{9} & NS \\
\hline Delay from thermal injury (d) & $2 \cdot 1$ & 0.2 & $2 \cdot 4$ & 0.2 & NS \\
\hline $\begin{array}{l}\text { Abbreviated Burn Severity } \\
\text { Index }\end{array}$ & $8 \cdot 7$ & 0.5 & $8 \cdot 7$ & 0.5 & NS \\
\hline Total burned surface area (\%) & 38.5 & $4 \cdot 0$ & 37.4 & 4.9 & NS \\
\hline Glucose (mg/dl) & $102 \cdot 9$ & $6 \cdot 2$ & $109 \cdot 0$ & $7 \cdot 2$ & NS \\
\hline Blood white cells $\left(\times 10^{3} / \mu \mathrm{l}\right)$ & $7 \cdot 74$ & 1.05 & 11.44 & $1 \cdot 13$ & 0.018 \\
\hline
\end{tabular}

Plasma phospholipid fatty acids

Changes in plasma phospholipid fatty acids from D1 to D6 were not statistically different between groups, except for oleic acid, which increased significantly in group $\mathrm{O}$ compared with group M $(P<0 \cdot 001$; Table 4).

Plasma levels of LA decreased significantly in both groups ( -5.06 (SEM 0.65), $P=0.004$, and -2.52 (SEM 0.91), $P=0.05$, in groups $\mathrm{O}$ and $\mathrm{M}$, respectively). This variation was associated with a statistically significant decrease in AA level $(-1.32$ (SEM 0.43), $P=0.01$, and -2.52 (SEM 0.91), $P=0.03$, in groups $\mathrm{O}$ and $\mathrm{M}$, respectively). Nevertheless, the conversion of LA to its $\mathrm{C} 20-\mathrm{C} 22$ derivatives was actually maintained, as illustrated by the evolution of the AA:LA ratio, which remained unchanged, and the ratio between the sum of LA upper derivatives and LA, which increased significantly ( $P=0.03$ in both groups). The rise

Table 3. Parenteral intakes during the study period for groups of patients administered parenteral nutrition including olive oil $(\mathrm{O})$ or medium-chain/long-chain triacylglycerol (M) based lipid emulsions

(Mean \pm SEM)

\begin{tabular}{|c|c|c|c|c|c|}
\hline & \multicolumn{2}{|c|}{$\mathrm{O}(n 11)$} & \multicolumn{2}{|c|}{$\mathrm{M}(n 11)$} & \multirow[b]{2}{*}{$P$} \\
\hline & Mean & SEM & Mean & SEM & \\
\hline Treatment duration (d) & $5 \cdot 1$ & 0.6 & $6 \cdot 0$ & 0.0 & NS \\
\hline $\begin{array}{l}\text { Lipid infusion } \\
\quad \text { duration (h) }\end{array}$ & 21.4 & 0.8 & $22 \cdot 8$ & 0.2 & 0.012 \\
\hline$N(g / k g$ per $d)$ & 0.24 & 0.00 & 0.24 & 0.00 & NS \\
\hline Glucose (g/kg per d) & 4.9 & 0.1 & $4 \cdot 8$ & $0 \cdot 1$ & NS \\
\hline Lipid (g/kg per d) & $1 \cdot 3$ & 0.0 & $1 \cdot 3$ & 0.0 & NS \\
\hline Volume (ml/d) & 2336 & 141 & 2490 & 93 & NS \\
\hline $\begin{array}{l}\text { Non-protein energy } \\
(\mathrm{kJ} / \mathrm{kg} \text { per } \mathrm{d})\end{array}$ & $129 \cdot 7$ & 1.6 & $129 \cdot 7$ & $1 \cdot 2$ & NS \\
\hline $\begin{array}{l}\text { Total energy } \\
(\mathrm{kJ} / \mathrm{kg} \text { per } \mathrm{d})\end{array}$ & $154 \cdot 9$ & 1.6 & 154.9 & $1 \cdot 6$ & NS \\
\hline $\begin{array}{l}\text { Lipid (\% of } \\
\text { non-protein energy) }\end{array}$ & $37 \cdot 0$ & 0.5 & 37.4 & 0.6 & NS \\
\hline $\begin{array}{l}\text { Glucose (\% of } \\
\text { non-protein energy) }\end{array}$ & $63 \cdot 0$ & 0.5 & $62 \cdot 6$ & 0.6 & NS \\
\hline
\end{tabular}

NS, $P>0.05$ by the Wilcoxon rank sum test for all parameters. 
in di-homo- $\gamma$-linolenic acid (C20:3n-6) level in both groups $(P=0.004$ and $P=0.002$ in groups $\mathrm{O}$ and $\mathrm{M}$, respectively) also contrasted with the fall in AA. In addition, the triene:tetraene ratio, although increasing in both groups, remained mainly below the threshold of 0.2 in all patients, indicating that the patients did not develop essential fatty acid deficiency. Conversely, $n-3: n-6$ ratios were decreased in both groups $(P=0.004$ and $P=0.007$ in groups $\mathrm{O}$ and $\mathrm{M}$, respectively).

\section{Nutritional and inflammatory status}

The change in the patients' nutritional and inflammatory parameters, including plasma cytokines, did not differ statistically between groups (Tables 5 and 6 ).

\section{Liver function tests}

After the $6 \mathrm{~d}$ period of infusion, abnormal values were more frequent in group $M$ (Table 7). Markers of cholestasis occurred during TPN in three out of nine patients in group $\mathrm{O}$, compared with nine out of eleven patients in group $\mathrm{M}$. This difference was statistically significant between the two groups $(P=0.04$, Suissa-Shuster test). Markers of cytolysis were also associated with cholestasis in two group $\mathrm{O}$ and three group $\mathrm{M}$ patients.

The comparative analysis of clinical and laboratory characteristics of the groups of patients with and without liver function abnormalities (twelve $v$. ten, respectively) showed that there were no statistical differences for age, gender ratio, BMI, Abbreviated Burn Severity Index, parenteral intake or incidence of sepsis. Also, the baseline of and changes in plasma glucose, phospholipid fatty acid profiles and inflammatory parameters including cytokines were not significantly different when comparing patients who had liver abnormalities with the remaining patients.

\section{Other laboratory parameters}

Plasma lipid changes did not differ statistically between the two groups (Table 5). Plasma triacylglycerols increased between 1 and 2 ULN in three patients in each group and above 2 ULN in one patient from group M. Total cholesterol was either within the normal range at baseline, or was below normal in two patients from each group. It remained stable or normalised over time in all cases except for two patients in group M, who showed a decrease. (Paired data are missing for two patients from group O.)

Hyperglycaemia occurred or increased in both groups, between 1 and 2 ULN in five group $\mathrm{O} v$. three group M patients, and above $2 \mathrm{ULN}$ in three group $\mathrm{O} v$. two group $\mathrm{M}$ patients. There was no statistical difference between groups regarding changes in all other routinely assessed laboratory parameters (data not shown).

\section{Adverse events and clinical outcome}

During the $6 \mathrm{~d}$ period of TPN, septicaemia or documented infections of the lungs or burn area were diagnosed in six patients from each group.

After the completion of TPN, seven patients died from multiple organ failure during their stay in ICU (from 4 to $37 \mathrm{~d}$ after the last infusion of TPN, occurring in four patients from group $\mathrm{O}$, including one case of a premature end at D2, and in three patients from group $\mathrm{M}$ ). No other death was observed during the 6-month 
Table 5. Change in plasma of lipids, nutritional and inflammatory parameters during parenteral nutrition for groups of patients administered parenteral nutrition including olive oil $(\mathrm{O})$ or medium-chain/long-chain triacylglycerol $(\mathrm{M})$ based lipid emulsions

(Mean \pm SEM)

\begin{tabular}{|c|c|c|c|c|c|c|c|c|c|c|c|}
\hline & \multicolumn{4}{|c|}{$\mathrm{O}\left(n^{*} 9\right)$} & \multirow[b]{3}{*}{$P \S$} & \multicolumn{4}{|c|}{$\mathrm{M}\left(n^{*} 11\right)$} & \multirow[b]{3}{*}{$P \S$} & \multirow[b]{3}{*}{$P$ between groups } \\
\hline & \multicolumn{2}{|c|}{ D1 } & \multicolumn{2}{|c|}{ D6 } & & \multicolumn{2}{|c|}{ D1 } & \multicolumn{2}{|c|}{ D6 } & & \\
\hline & Mean & SEM & Mean & SEM & & Mean & SEM & Mean & SEM & & \\
\hline Total proteins $(\mathrm{mg} / \mathrm{dl})$ & $4 \cdot 0$ & 0.3 & 4.9 & 0.3 & 0.008 & $4 \cdot 0$ & 0.2 & $5 \cdot 1$ & 0.2 & $0.009+$ & NS \\
\hline Albumin (mg/dl) & $2 \cdot 4$ & 0.2 & $2 \cdot 4$ & 0.1 & NS & $2 \cdot 5$ & 0.2 & $2 \cdot 5$ & 0.2 & NS† & NS \\
\hline Triacylglycerols (mg/dl) & 115 & 15 & 185 & 30 & 0.012 & 124 & 14 & 193 & 28 & $0.014 \dagger$ & NS \\
\hline Glycaemia (mg/dl) & 104 & 8 & 211 & 49 & 0.012 & 109 & 7 & 163 & 31 & 0.006 & NS \\
\hline Haemoglobin (g/dl) & 11.5 & 0.8 & $10 \cdot 1$ & 0.5 & NS & $12 \cdot 4$ & 0.4 & $10 \cdot 6$ & 0.3 & 0.032 & NS \\
\hline C-reactive protein (mg/dl) & 11.5 & $1 \cdot 1$ & $11 \cdot 7$ & 2.5 & NSt & $12 \cdot 1$ & $1 \cdot 2$ & $11 \cdot 1$ & 1.8 & NS‡ & NS \\
\hline Fibrinogen (mg/dl) & 596 & 42 & 742 & 42 & 0.039 & 651 & 43 & 750 & 42 & 0.024 & NS \\
\hline Platelets $\left(10^{9} / \mu \mathrm{l}\right)$ & 114 & 11 & 291 & 37 & 0.004 & 140 & 21 & 351 & 37 & 0.001 & NS \\
\hline
\end{tabular}

NS, $P>0.05$ by the Wilcoxon rank sum test for all parameters.

* Number of patients in each group with available sample for a paired analysis.

$\dagger n 8$ and $\ddagger n 10$ for a paired analysis.

$\S$ Wilcoxon signed rank test for intra-group comparisons over time.

follow-up. For each death, a pre-existing severe sepsis as defined by Bone (1992) was identified as a direct causative event.

When comparing the patients who died $(n 7)$ with those who did not ( $n$ 15), patients did not differ at baseline in terms of BMI, Abbreviated Burn Severity Index, inflammatory parameters, triacylglycerols, total cholesterol and serum albumin values (Table 8). Their parenteral intakes were not statistically different. For the seven patients who died, the burn was associated with an inhalation trauma, but this characteristic of thermal injury severity (German et al. 1997) did not make them statistically different from the other patients. Conversely, they were statistically different from the patients who lived $(n$ 15) on three characteristics: age; hyperglycaemia at baseline; change in plasma cytokine levels. Indeed, the individuals who died were older and significantly more often hyperglycaemic $(>110 \mathrm{mg} / \mathrm{dl})$ at baseline. The relative risk of mortality in the 6 months following the thermal injury was about 8.5 times higher for patients who were hyperglycaemic at baseline $(\mathrm{RR}=8.5 ; 95 \%$ CI 2.3, 31.2). Considering the cytokine analysis, IL-6 evolved differently, its level continuing to increase in the group of patients with fatal sepsis while decreasing in the other patients.

Change in multiple organ dysfunction score, duration of ventilation (11.0 (SEM 3.6) v. 13.0 (SEM 4.9) d), length of stay in ICU (32.9 (SEM 3.2) v. 41.8 (SEM 5.6) d) and in hospital (57 (SEM 4.6) v. 64.9 (SEM 8.2) d) were not statistically different between groups $\mathrm{O}$ and $\mathrm{M}$.

\section{Discussion}

Profound alterations in fatty acid metabolism following burn injury have been reported (Cetinkale \& Yazici, 1997, Pratt et al. 2001) and consequently represent a fundamental process in the genesis of the post-injury immunosuppressive and hyper-inflammatory state. In particular, plasma and cell membrane levels of phospholipid LA and of LA's higher derivatives, including AA, fall early, this being characterised by a prolonged and progressive deterioration during at least the first 2 weeks following thermal injury. The changes in fatty acid profile are greatest around $7-10 \mathrm{~d}$ after the burn and occur concomitantly with the highest impact on immunity and on the production of inflammatory mediators (Pratt et al. 2002).

This is the first time that the effects of parenteral nutrition on fatty acid metabolism in thermally injured patients have been studied and reported. This study was exploratory in nature because an olive-oil based lipid emulsion has never previously been compared with an MCT/LCT lipid emulsion in critically ill patients. The choice of MCT/LCT as a comparator was made as this was the referenced lipid emulsion in the study centre. It is better justified than a high LA-content lipid emulsion with potentially deleterious effects on immunity and inflammation. In the present study, the comparative assessment of the two lipid emulsions with restricted LA content confirms both a similar improvement over time of fatty acid metabolism (LA elongation to di-homo- $\boldsymbol{\gamma}$-linolenic acid) and their global safety in severely burned patients.

Consistent with previously published data, there was at D6 (corresponding to $7-9 \mathrm{~d}$ after thermal injury) a decrease in LA and AA, possibly explained in part as the consequence of series 2 prostaglandin biosynthesis from AA oxidative metabolism (Karlstad et al. 1993). However, we found in both groups a statistical increase in the sum of $n-6$ higher derivatives, the AA:LA ratio and the level of di-homo- $\gamma$-linolenic acid $(\mathrm{C} 20: 3 n-6)$, the immediate precursor for series 1 prostaglandins, which are considered as anti-aggregatory, anti-inflammatory eicosanoids. These findings can be interpreted as reflecting the beneficial effect on LA metabolism of a reduced LA-content lipid emulsion despite the sustained inflammatory response observed in severely burned patients.

Although no significant difference in global safety was found between lipid emulsions, a statistically higher number of patients experienced liver function abnormalities with MCT/LCT, raising concern regarding the tolerability of this lipid emulsion or suggesting a better preservation of liver function with an olive/soyabean oil lipid emulsion.

It has been previously reported that liver function can be impaired in severely burned patients (Herndon et al. 1987). Early hepatic changes result from shock and hypovolaemia, but more significant changes occur later as a result of sepsis and other complicating factors (Friedman \& Deppe, 2002). In addition, liver function abnormalities are very common in parenterally fed 

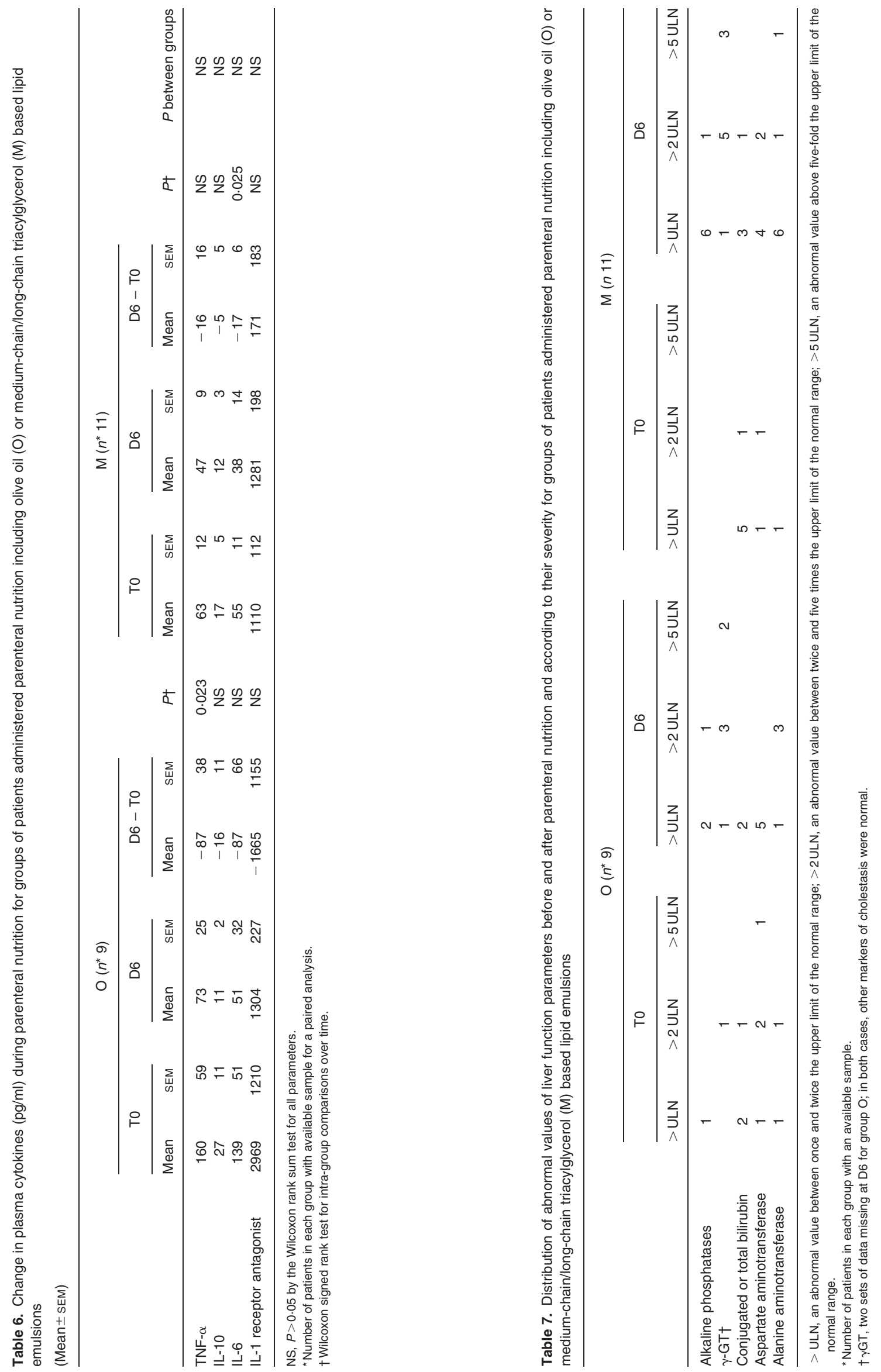
Table 8. Comparison between patients with fatal sepsis $v$. others for groups of patients administered parenteral nutrition including olive oil (O) or medium-chain/long-chain triacylglycerol (M) based lipid emulsions

(Mean \pm SEM or $n$ )

\begin{tabular}{|c|c|c|c|c|c|}
\hline & \multicolumn{2}{|c|}{ Fatal sepsis } & \multicolumn{2}{|c|}{ Patients staying alive } & \multirow[b]{3}{*}{$P$} \\
\hline & \multicolumn{2}{|c|}{$(n 7)$} & \multicolumn{2}{|c|}{$(n 15)$} & \\
\hline & Mean & SEM & Mean & SEM & \\
\hline Group membership (O/M) & \multicolumn{2}{|c|}{$4 \dagger / 3$} & \multicolumn{2}{|c|}{$7 \dagger / 8$} & NS \\
\hline Total burn surface area (\%) & 42 & $7 \cdot 5$ & 36 & $3 \cdot 0$ & NS \\
\hline Abbreviated Burn Severity Index & $9 \cdot 57$ & 0.69 & 8.33 & 0.33 & NS \\
\hline Age (years) & $57 \cdot 1$ & $6 \cdot 12$ & $38 \cdot 6$ & 3.45 & 0.012 \\
\hline Hyperglycaemia* at baseline $(n(\%))$ & \multicolumn{2}{|c|}{$5(71 \%)$} & \multicolumn{2}{|c|}{$0(0 \%)$} & 0.001 \\
\hline Glycaemia change (mg/dl) (D6 - D1) & $129 \cdot 5$ & $65 \cdot 0$ & $55 \cdot 5$ & 21.5 & NS \\
\hline C-reactive protein at baseline $(\mathrm{mg} / \mathrm{dl})$ & 126 & $13 \cdot 2$ & 118 & 8.9 & NS \\
\hline Fibrinogen at baseline (mg/dl) & 691 & 58 & 612 & 31 & NS \\
\hline IL-6 at baseline (pg/l) & 174 & 117 & 103 & 33 & NS \\
\hline IL-6\% change (pg/l) (D6 - D1) & 77 & 110 & -62 & 9 & 0.035 \\
\hline
\end{tabular}

NS, $P>0.05$ by the Wilcoxon rank sum test for all parameters.

* Glycaemia > upper limit of normal, which is $120 \mathrm{mg} / \mathrm{dl}$.

† Including one case of premature death at D1.

patients, although they usually occur during prolonged TPN (Capron et al. 1983; Garcia-de-Lorenzo, 1983; Beau et al. 1994; Alpers, 2001). In the present study, whereas several causal factors could be suggested (patient characteristics, severity of burn injury, sepsis), none has been specifically identified to explain the difference in the occurrence of these abnormal hepatic changes.

From an analysis of previous clinical studies, ClinOleic's hepatic tolerability has thus far been revealed as being at least equivalent to that observed with soyabean oil-based emulsions (Bouletreau et al. 1996; Masini et al. 1996; De Francesco et al. 1999; Goulet et al. 1999; Vahedi et al. 1999; Thomas-Gibson et al. 2004). Moreover, several experiments carried out in rats have shown the following benefits when using ClinOleic. First, it has been demonstrated that ClinOleic does not have a significant effect on biliary secretion, unlike soyabean oil emulsions (Ythier-Moury et al. 1990). Second, Garnacho et al., in a model of Gram-negative bacteraemia, have recently compared ClinOleic with MCT/LCT and soyabean oil-based LCT lipid emulsions. The mononuclear phagocyte system functions were better preserved with the olive oil-enriched lipid emulsion. Bacterial clearance from the animals' liver, spleen and lungs was significantly impaired in animals parenterally fed with the other two emulsions when compared with the control group of orally fed animals (Garnacho-Montero, 2002).

Concerning MCT/LCT, experimental studies have also provided advantageous findings. It has been proposed that MCT preserve gut permeability and the pathological liver changes induced by lipopolysaccharide (Kono et al. 2003). On the other hand, this is not the first time that a deterioration in liver function has been reported with the use of this lipid emulsion (Beau et al. 1995) although no convincing explanation has been given to support this observation. In addition, short infusions of MCT/LCT lipid emulsions in human subject have been shown to increase total lipid and cholesterol concentration in the bile and increase gallbladder bile lithogenicity in patients with (Pakula et al. 1999) and without (Rubin et al. 1992, 1996) gallstones. A recent study performed on septic patients who required TPN showed that MCT/LCT infusion, when compared with soyabean oil emulsions, led to an increase in plasma triacylglycerols and total and free cholesterol (Charcon Castro et al. 2000). Finally, it must be remembered that lipid emulsions manufactured differently appear to induce different side-effects even when the basic ingredients are the same (Chambrier et al. 1999).

Sepsis continues to be a significant cause of mortality after the acute phase of major burns (McManus et al. 1985). In the current trial, the number of septic complications, with their high level of mortality, is consistent with previous observations and is partly explained by the high Abbreviated Burn Severity Index scores and frequency of patients with inhalation trauma (German et al. 1997).

In the current study, other mortality risk factors of the post-burn period have been either validated (age, change in cytokines) or elicited (hyperglycaemia after the resuscitation period and pre-existing before starting TPN). In accordance with the recent trial of Van den Berghe et al. (2001), which confirmed that hyperglycaemia of even a moderate level could increase mortality risk in ICU patients, we have shown an 8.5-fold increase in relative risk of mortality in the 6 months following thermal injury for patients who were hyperglycaemic before starting TPN. In these patients, hyperglycaemia is better explained by thermal injury and its related stress rather than by solutions of glucose infused into some of them. Concerning the potential capacity of MUFA-enriched emulsions to improve glucose homeostasis (Rocca et al. 2001), a 6 d period was probably too short to demonstrate any effect.

Finally, a few studies have investigated the effect of intravenous lipid emulsions upon cytokine production. These studies mainly aimed to demonstrate the immunosuppressive effects of soyabean oil-based lipid emulsions and the potential role of alternative lipid emulsions such as MCT/LCT (Bellinati-Pires et al. 1993; Waitzberg et al. 1997), structured lipids (Wanten et al. 2000), fish oil (Morlion et al. 1996) or olive oil-based lipid emulsions (Granato et al. 2000; Moussa et al. 2000). The results of the present trial are in accordance with current knowledge:

1. The levels of pro- and anti-inflammatory cytokines tend to decrease but are still high within $10 \mathrm{~d}$ following severe burns (Guo et al. 1990; Drost et al. 1993; Endo et al. 1996; Yamada et al. 1996; Carsin et al. 1997). 
2. The change in IL-6, with a persistent increase in the patients who died, is proving to be a reliable predictor of fatality, as previously shown (Ueyama et al. 1992; Kowal-Vern et al. 1994; Papini et al. 1997).

In conclusion, the use of parenteral nutrition with lipid emulsions with a restricted LA content is efficient in reversing the impairment in essential fatty acid metabolism usually seen in severely burned patients. The difference found in terms of changes in hepatic parameters would be an advantage for the olive oil/soyabean oil-based lipid emulsion, making it a good alternative for the parenteral nutrition of severely burned patients.

\section{Acknowledgements}

The determination and interpretation of plasma cytokines were performed by Professor JM Cavaillon, Institut Pasteur, Unité d'Immuno-Allergologie, 28 rue du Dr Roux 75015 Paris, France. This work was supported by a grant from Baxter S.A.S., 78311 Maurepas, France, and was presented in abstract form at the Twenty-second ESPEN Congress, Madrid, Spain, September 2000 (Clin Nutr 2000; 19, Suppl. 1, 43).

\section{References}

Alexander JW (1990) Mechanism of immunologic suppression in burn injury. J Trauma 30, 70S-75S.

Alpers DH (2001) Liver complications and failure in patients on home parenteral nutrition. Curr Opin Gastroenterol 17, 147-149.

Barlow Y (1994) T lymphocytes and immunosuppression in the burned patient: a review. Burns 20, 487-490.

Battistella FD, Widergren JT, Anderson JT, Siepler JK, Weber JC \& MacColl K (1997) A prospective, randomized trial of intravenous fat emulsion administration in trauma victims requiring total parenteral nutrition. J Trauma 43, 52-60.

Beau P, Barrioz T \& Ingrand P (1994) Is parenteral nutrition-related cholestatic liver disease an infectious disease? Gastroenterol Clin Biol 18, 63-67.

Beau P, de Lédinghen V \& Ingrand P (1995) Total parenteral nutritionrelated liver disease and medium chain triglycerides lipid emulsions. Nutr Clin Metabol 9, 117-122.

Bellinati-Pires R, Waitzberg DL, Salgado MM \& Carneiro-Sampaio MM (1993) Functional alterations of human neutrophils by medium-chain triglyceride emulsion: evaluation of phagocytosis, bacterial killing, and oxidative activity. J Leukoc Biol 53, 404-410.

Bone RC (1992) Definitions for sepsis and organ failure and guidelines for the use of innovative therapies in sepsis. The ACCP/SCCM Consensus Conference Committee. American College of Chest Physicians/Society of Critical Care Medicine. Chest 101, 1644-1655.

Bouletreau P, Berrada K \& Chambrier C (1996) Tolérance hépatique de l'émulsion lipidique ClinOleic ${ }^{\circledR}$. Nutr Clin Métabol 10, 335-365.

Calder PC \& Newsholme EA (1992) PUFAs suppress human peripheral blood lymphocytes proliferation and interleukin-2 production. Clin Sci 75, 695-700.

Capron JP, Gineston JL, Hervé MA \& Braillon A (1983) Metronidazole in prevention of cholestasis associated with total parenteral nutrition. Lancet 1, 446-447.

Carsin H, Assicot M, Feger F, Roy O, Pennacino I, Le Bever H, Ainaud P \& Bohuon C (1997) Evolution and significance of circulating procalcitonin levels compared with IL-6, TNF alpha and endotoxin levels early after thermal injury. Burns 23, 218-224.

Cavicchi M, Bean P, Crenn P, Degott C \& Messing B (2000) Prevalence of liver disease and contributing factors in patients receiving home parenteral nutrition for permanent intestinal failure. Ann Intern Med 132, 525-532.

Cetinkale O \& Yazici Z (1997) Early postburn fatty acid profile in burn patients. Burns 23, 392-399.

Chambrier C, Guiraud M, Gibault JP, Labrosse H \& Bouletreau P (1999) Medium- and long-chain triacylglycerols in postoperative patients: structured lipids versus a physical mixture. Nutrition 15, 274-277.

Charcon Castro MP, Jimenez Sesé B, Salvado Salvat J, Sabin Urquia P, Pascual Mostaza C \& Planas Vila M (2000) Influence of two fatty emulsions with a different triglyceride composition on the lipid metabolism of the septicemic patient. Nutr Hosp 15, 13-17.

De Francesco A, Balzola FA, Come A, Le Brun A, Evard D, Atlan P, Dutot G \& Balzola F (1999) Long-term safety of home parenteral nutrition (HPN) with a new olive oil-based lipid emulsion (LE): a randomised, double-blind, comparative trial. Clinical Nutrition 18, Suppl. $1,46$.

Deitch EA (1995) Nutrition support of the burn patient. In Nutrition in the Critically Ill Patient, pp. 735-750 [CH Lang, editor]. Philadelphia: WB Saunders.

Driss F, Darcet P, Delhaye N \& Mendy F (1988) Effect of eicosapentanoic acid on RBC filterability and fatty acid composition. Clin Hemorrheol 8, 679-685.

Drost AC, Burleson DG, Cioffi WG Jr, Jordan BS, Mason AD Jr \& Pruitt BA Jr (1993) Plasma cytokines following thermal injury and their relationship with patient mortality, burn size, and time postburn. J Trauma 35, 335-339.

Endo S, Inada K, Yamada Y, et al. (1996) Plasma levels of interleukin-1 receptor antagonist (IL-1ra) and severity of illness in patients with burns. J Med 27, 57-71.

Eritsland J (2000) Safety considerations of polyunsaturated fatty acids. Am J Clin Nutr 71, 197S-201S.

Freeman J, Goldmann DA, Smith NE, Sidebottom DG, Epstein ME \& Platt R (1990) Association of intravenous lipid emulsion and coagulase-negative staphylococcal bacteremia in neonatal intensive care units. $N$ Engl J Med 323, 301-308.

Friedman B \& Deppe SA (2002) Nutritional considerations in the severely burned patient. In Nutritional Considerations in the Intensive Care Unit, pp. 245-258 [SA Shirota, RG Martindale and SD Scwaitzberg, editors]. Silver Spring, CO: Kendall/Hunt Publishing Company \& ASPEN.

García-de-Lorenzo A (1983) Metronidazole, cholestasis and total parenteral nutrition. Lancet 21, 1161.

Garcia-de-Lorenzo A \& Culebras JM (1992) Linoleic acid and the immune system. Controversies about lipid emulsions. Nutr Hosp 7, $377-387$

Garnacho-Montero J, Ortiz-Leyba C, Garnacho-Montero MC, GarciaGarmendia JL, Perez-Paredes C, Moyano-Del Estad MR, Barrero-Almodovar A \& Jimenez-Jimenez FJ (2002) Effects of three intravenous lipid emulsions on the survival and mononuclear phagocyte function of septic rats. Nutrition 18, 751-754.

Garrel DR, Razi M, Lariviere F, Jobin N, Naman N, Emptoz-Bonneton A \& Pugeat MM (1995) Improved clinical status and length of care with low-fat nutrition support in burn patients. J Parenter Enter Nutr 19, $482-491$

German G, Barthold U, Lefering R, Raff T \& Hartmann B (1997) The impact of risk factors and pre-existing conditions on the mortality of burn patients and the precision of predictive admission-scoring systems. Burns 23, 195-203.

Gobel Y, Koletzko B, Bohles HJ, Engelsberger I, Forget D, Le Brun A, Peters J \& Zimmermann A (2003) Parenteral fat emulsions based on olive and soybean oils: a randomized clinical trial in preterm infants. J Pediatr Gastroenterol Nutr 37, 161-167.

Goulet O, De Potter S, Antebi H, et al. (1999) Long-term efficacy and safety of a new olive oil-based intravenous fat emulsion in paediatric patients: a double blind randomized study. Am J Clin Nutr 70, $338-345$. 
Granato D, Blum S, Rössle C, Le Boucher J, Malnoe A \& Dutot G (2000) Effects of parenteral lipid emulsions with different fatty acid composition on immune cell functions in vitro. J Parenter Enter Nutr 24, $113-118$.

Guo Y, Dickerson C, Chrest FJ, Adler WH, Munster AM \& Winchurch RA (1990) Increased levels of circulating interleukin 6 in burn patients. Clin Immunol Immunopathol 54, 361-371.

Hageman JR, McCulloch K, Gora P, Olsen EK, Pachman L \& Hunt CE (1983) Intralipid alterations in pulmonary prostaglandin metabolism and gas exchange. Crit Care Med 11, 794-798.

Herndon DN, Stein MD, Rutan TC, Abston S \& Linares H (1987) Failure of TPN supplementation to improve liver function, immunity, and mortality in thermally injured patients. J Trauma 27, 195-204.

Herruzo-Cabrera R, Fernandez-Arjona M, Garcia-Torres V, MartinezRatero S, Lenguas-Portero F \& Rey-Calero J (1995) Mortality evolution study of burn patients in a critical care burn unit between 1971 and 1991. Burns 21, 106-109.

Holman RT (1960) The ratio of trienoic:tetraenoic acids in the tissue lipids as a measure of essential fatty acid requirement. J Nutr 70, 405-410.

Karlstad MD, DeMichele SJ, Leathem WD \& Peterson MB (1993) Effect of intravenous lipid emulsions enriched with gamma-linolenic acid on plasma n-6 fatty acids and prostaglandin biosynthesis after burn and endotoxin injury in rats. Crit Care Med 21, 1740-1749.

Kinsella JE, Lokesh B, Broughton S \& Whelan J (1990) Dietary polyunsaturated fatty acids and eicosanoids: potential effects on the modulation of inflammatory and immune cells: an overview. Nutrition 6, 24-44.

Kono H, Fujii H, Asakawa M, Matsuda M, Maki A \& Matsumoto Y (2003) Protective effects of medium-chain triglycerides on the liver and gut in rats administered endotoxin. Ann Surg 237, 246-255.

Kowal-Vern A, Walenga JM, Hoppensteadt D, Sharp-Pucci M \& Gamelli RL (1994) Interleukin-2 and interleukin-6 in relation to burn wound size in the acute phase of thermal injury. J Am Coll Surg 178, 357-362.

McManus AT, Mason AD Jr, McManus WF \& Pruitt BA Jr (1985) Twenty-five year review of Pseudomonas aeruginosa bacteremia in a burn center. Eur J Clin Microbiol 4, 219-223.

Masini JP, Fichelle A, Pescio M, Béréziat G, Desmonts JM \& Lienhart A (1996) Tolérance clinique et biologique et effets sur les paramétres lipidiques de ClinOleic ${ }^{\circledR}$ comparé à l'Intralipide ${ }^{\circledR}$ chez des patients de réanimation chirurgicale. Nutr Clin Métabol 10, 21S-24S.

Montegut WJ \& Lowry SF (1993) Nutrition in burn patients. Semin Nephrol 13, 400-408.

Morlion BJ, Torwesten E, Lessire H, Sturm G, Peskar BM, Furst P \& Puchstein C (1996) The effect of parenteral fish oil on leukocyte membrane fatty acid composition and leukotriene-synthesizing capacity in patients with postoperative trauma. Metabolism 45, 1208-1213.

Moussa M, Le Boucher J, Garcia J, Tkaczuk J, Ragab J, Dutot G, Ohayon E, Ghisolfi J \& Thouvenot JP (2000) In vivo effects of olive oil-based lipid emulsion on lymphocyte activation in rats. Clin Nutr 19, 49-54.

Nordenstrom J, Jarstrand C \& Wirniek A (1979) Decreased chemotactic and random migration of leukocytes during intralipid infusion. Am J Clin Nutr 32, 2416-2420.

Pakula R, Konikoff FM, Moser AM, Greif F, Tietz A, Gilat T \& Rubin M (1999) The short term lipid infusion on plasma and hepatic bile lipids in humans. Gut 45, 453-458.

Papini RP, Wilson AP, Steer JA, Hill G, McGrouther DA \& Parkhouse N (1997) Plasma concentrations of tumour necrosis factor-alpha and interleukin-6 during burn wound surgery or dressing. Br J Plast Surg 50, $354-361$

Peck MD (1994) Interaction of lipids with immune function. I. Biochemical effects of dietary lipids on plasma membranes. J Nutr Biochem 5, 466-478.

Pelaez J, Garcia-de-Lorenzo A, Denia R, Martinez-Ratero S, Lopez J \& Caparros T (1997) Nutritional support for the large burn patient. Nutr Hosp 12, 121-133.
Pratt VC, Tredget EE, Clandinin MT \& Field CJ (2001) Fatty acid content of plasma lipids and erythrocyte phospholipids are altered following burn injury. Lipids 36, 675-682.

Pratt VC, Tredget EE, Clandinin MT \& Field CJ (2002) Alterations in lymphocyte function and relation to phospholipid composition after burn injury in humans. Crit Care Med 30, 1753-1761.

Reimer T, Morlion B, Fürst P, Le Brun A, Atlan P, Dutot G \& Puchstein C (2001) Effects of an olive oil based intravenous lipid emulsion (ILE) on plasma and leukocyte membrane fatty acid (FA) composition and on clinical outcomes in postoperative patients. Clin Nutr 20, suppl. 40.

Rocca AS, LaGreca J, Kalitsky J \& Brubaker PL (2001) Monounsaturated fatty acid diets improve glycemic tolerance through increased secretion of glucagon-like peptide-1. Endocrinology 142, 1148-1155.

Rossle C, Breton I, Bereziat G, et al. (1992) Evolution of plasma phospholipid FA pattern in patients receiving postoperative TPN including soybean oil or olive oil-based lipid emulsions: a comparative multicenter study. Clin Nutr 11, suppl. 19.

Rubin M, Halpern Z, Charach G, Dvir A, Antebi E, Gilat T \& Lichtenberg D (1992) Effect of lipid infusion on bile composition and lithogenicity in patients without cholesterol gallstones. Gut 33, 1400-1403.

Rubin M, Pakula R, Moser A, Halpern Z, Shimonov M \& Lichtenberg D (1996) Does lipid infusion affect bile composition in humans? Isr J Med Sci 32, 1308-1313.

Sadeghi S, Wallace FA \& Calder PC (1999) Dietary lipids modify the cytokine response to bacterial lipopolysaccharide in mice. Immunology 96, 404-410.

Schwacha MG \& Chaudry IH (2002) The cellular basis of post-burn immunosuppression: macrophages and mediators. Int J Mol Med 10, 239-243.

Seidner DL, Mascioli EA, Istfan NW, Porter KA, Selleck K, Blackburn GL \& Bistrian BR (1989) Effects of long-chain triglyceride emulsions on reticuloendothelial system function in humans. J Parenter Enter Nutr 13, 614-619.

Sparkes BG (1997) Immunological responses to thermal injury. Burns 23, $106-113$.

Spielmann D, Bracco U, Traitler H, Crozier G, Holman R, Ward M \& Cotter R (1988) Alternative lipids to usual n-6 PUFAS: $\gamma$-linolenic acid, $\alpha$-linolenic acid, stearidonic acid, EPA, etc. J Parenter Enter Nutr 12, 111S-123S

Suissa S \& Shuster JJ (1985) Exact unconditional sample sizes for the 2 by 2 binomial trial. J Roy Statist Soc A148, 317-327.

Thomas-Gibson S, Jawhari AU, Atlan P, Le Brun A, Farthing A \& Forbes A (2004) Safe and efficacious prologed use of an olive oil-based lipid emulsion (ClinOleic) in chronic intestinal failure. Clin Nutr $\mathbf{2 3}$ $697-703$.

Tobiasen J, Hiebert JM \& Edlich RF (1982) The abbreviated burn severity index. Ann Emerg Med 11, 260-262.

Ueyama M, Maruyama I, Osame M \& Sawada Y (1992) Marked increase in plasma interleukin-6 in burn patients. J Lab Clin Med 120, 693-698.

Vahedi K, Bereziat G, Le Brun A, Perennec V, Evard D, Atlan P, Dutot G \& Messing B (1999) A randomised, double-blind 3-month study in home parenteral nutrition (HPN) patients with olive or soy oil-based lipid emulsions (ILE): safety, nutritional status, plasma and cell-membrane fatty acid profiles. Clin Nutr 18, Suppl. 48.

Van den Berghe G, Wouters P, Weekers F, Verwaest C, Bruyninckx F, Schetz M, Vlasselaers D, Ferdinande P, Lauwers P \& Bouillon R (2001) Intensive insulin therapy in critically ill patients. $N$ Engl J Med 345, 1359-1367.

Waitzberg DL, Bellinati Pires R, Salgado MM, Hypolito IP, Colleto GM, Yagi O, Yamamuro EM, Gama-Rodrigues J \& Pinotti HW (1997) Effect of total parenteral nutrition with different lipid emulsions on human monocyte and neutrophils functions. Nutrition 13, 128-132.

Wanten GJA, Roos D \& Naber AHJ (2000) Effects of structurally different lipid emulsions on human neutrophil migration. Clin Nutr 19, 327-331.

Warden GD, Wilmore DW, Rogers PW, Mason AD \& Pruitt BA Jr (1973) Hypernatremic state in hypermetabolic burn patients. Arch Surg 106, 420-427. 
Weissman C (1999) Nutrition in the intensive care unit. Crit Care 3, $67 R-75 R$.

Yamada Y, Endo S \& Inada K (1996) Plasma cytokine levels in patients with severe burn injury with reference to the relationship between infection and prognosis. Burns 22, 587-593.
Ythier-Moury P, Dutot G \& Melin C (1990) Modifications of biliary secretion associated with parenteral nutrition in the rat: influence of fat emulsion composition. Clin Nutr 9, suppl. 26.

Zawacki BE, Azen SP, Imbus SH \& Chang YT (1979) Multifactorial probit analysis of mortality in burned patients. Ann Surg 189, 1-5. 